www.jmscr.igmpublication.org

Impact Factor 5.244

Index Copernicus Value: 83.27

ISSN (e)-2347-176x ISSN (p) 2455-0450

crossref DOI: _http://dx.doi.org/10.18535/jmscr/v4i8.01

Journal Of Medical Science And Clinical Research

\title{
Morbidity and Mortality Profile of Newborns Admitted to the Special Care Newborn Unit (SCNU) of A Teaching Hospital of Upper Assam, India - A Three Year Study
}

\author{
Authors \\ Manab Narayan Baruah ${ }^{1}$, Pankaj Pradeep Panyang ${ }^{2}$ \\ ${ }^{1,2}$ Department of Paediatrics, Jorhat Medical College, Jorhat, Assam, India \\ Corresponding Author \\ Dr Manab Narayan Baruah
}

Department of Paediatrics, Jorhat Medical College, Jorhat, Assam, India Pin: 785001.

Email: drmnbaruah@rediffmail.com

\begin{abstract}
Background: Neonatal mortality is the predominant cause of high infant and under five mortality rates. There is lack of data regarding the morbidity and mortality pattern of sick newborns admitted to special care neonatal units of Assam, especially studies done over an extended period of three years.

Aim: To study the morbidity and mortality profile of newborns admitted to the Special Care Newborn Unit of Jorhat Medical College \& Hospital.

Study design: Retrospective study for a period of three years $\left(1^{\text {ST }}\right.$ January 2013-31 $1^{\text {st }}$ December 2015.

Material and Methods: All sick newborns admitted to the SCNU during the study period were included in the study. Newborns admitted in the pediatric ward or PICU were excluded. The age, sex, birth weight, gestational age, morbidity, mortality data were collected from the standard monthly reporting format and patient case records.

Results: During the study period, a total of 8069 babies were admitted in the SCNU of which 6104(75.6\%) were admitted in the inborn unit while 1965(24.4\%) were admitted in the outborn unit. 58.4\% of babies were males and $42 \%$ were low birth weight $(<2,500 \mathrm{gm})$. Neonatal sepsis, jaundice and birth asphyxia were the common morbidities seen in the study. Sepsis was more common in the outborn compared to inborn (40\% vs 24\%). $87 \%$ of inborn and $72.6 \%$ outborn was successfully discharged from the SCNU. The mortality data shows much higher deaths in the outborn (13.6\%) compared to inborn unit (6.6\%). $77.5 \%$ of deaths were early neonatal deaths $\left(1^{\text {st }}\right.$ week of life). $66.1 \%$ of the death cases were low birth weight. Sepsis $(42.6 \%)$, birth asphyxia (29.3\%) and prematurity related complications $(17.5 \%)$ were the common causes of death. The case fatality rate of all causes of mortality were higher in the outborn versus inborn.

Conclusion: The burden of neonatal mortality is largely preventable. Strengthening of facility based care along with improved health care delivery at the peripheral level is essential to decrease neonatal mortality and ensure intact survival of sick newborns.
\end{abstract}

Key words: neonatal, morbidity, mortality, SCNU, inborn, outborn. 


\section{INTRODUCTION}

Globally every year four million babies die in the neonatal period ( $1^{\text {st }} 4$ weeks of life), with India contributing to one-fourth of the total mortality burden ${ }^{[1]} .75 \%$ of the neonatal deaths occur in the first week of life and at least $50 \%$ occur in the first day of life $\mathrm{e}^{[2]}$. While the under five mortality rate (U5MR) dropped by $30 \%$ from 74 per 1000 live births (2005-2006) to 52(2012), the Neonatal Mortality Rate(NMR) has been to slow to decline, decreasing by $22 \%$ from $37 / 1000$ live births to 29 $/ 1000$ live births during the same period. The current NMR of Assam is 29/1000 live births which is similar to the national NMR. Currently, $70 \%$ of infant deaths and more than $50 \%$ of under -five deaths are contributed by neonatal deaths. The Millennium Developmental Goal (MDG) 4 envisaged a two-third reduction of IMR by 2015 . The ENAP (Every Newborn Action Plan) recently endorsed by the World Health Assembly calls for NMR < 10/1000 live births by year 2035 in all countries. XII plan has set a goal of IMR of 25/1000 live births by 2017 which requires a NMR of $18 / 1000$ live births ${ }^{[3]}$. So, all efforts to reduce IMR/U5MR essentially have to focus on steps for sustained reduction of neonatal mortality. Evidence based interventions especially facility based care can lead to significant reduction in $\mathrm{NMR}^{[4]}$. Thus a three tiered facility based neonatal care has been started in India. Level I include the Newborn Stabilisation Unit (NBSU) at the First Referral Units (FRU), Level II refers to the Special Care Newborn Unit (SCNU) at the district hospital. Level III refers to the Neonatal ICU at a regional level. The SCNU provides a wide range of neonatal services for management of jaundice, LBW, sepsis and asphyxia with the exception of ventilation and surgical intervention ${ }^{[2]}$.

The SCNU of Jorhat Medical College was established in 2011 as a joint venture of GOI, UNICEF and NHM (National Health Mission). Being part of the medical college it caters not only to Jorhat but also the adjoining districts of Golaghat, Sivasagar as well as neighbouring Nagaland. Inspite of being a Level II unit
(SCNU), it provides advanced respiratory support like CPAP, mechanical ventilation, surfactant administration as well as exchange transfusion.

So the SCNU of Jorhat is a vital link in the efforts to decrease NMR of Jorhat as well of the entire state of Assam. There is lack of data regarding the profile of neonates admitted to SCNUs of the state. A better understanding of the morbidity and mortality profile of sick newborns admitted to SCNU will help in formulating policies for further decrease in the neonatal mortality in Assam.

Therefore a study was carried out to study the profile of newborns admitted in SCNU JMCH over a 3 year period (2013-2015) as studies done for an extended period was lacking in the region.

AIM OF THE STUDY: To study the morbidity and mortality profile of newborns admitted to the Special Care Newborn Unit of Jorhat Medical College \& Hospital.

\section{MATERIAL AND METHODS}

The study was carried out at the Special Care Newborn Unit (SCNU), Department of Pediatrics, Jorhat Medical College and Hospital.

The SCNU has total 26 beds with 20 inborn and 6 outborn beds. It is equipped with 26 radiant warmers, 15 phototherapy units, 6 bubble CPAP and 4 mechanical ventilators. Hospital stay, drugs and investigations are provided free of cost to all babies admitted in SCNU.

Study period: 3 years $\left(1^{\text {st }}\right.$ January $2013-31^{\text {st }}$ December 2015)

Study design: Retrospective study.

Inclusion criteria: All newborns (0-28days) admitted into the SCNU during the study period

Exclusion criteria: Babies > 28 days old, newborns admitted to pediatric ward/PICU were excluded from the study.

Data collection and analysis: Data was collected from the monthly records and patient files and compiled in MS excel. Data was analysed using appropriate statistical tools. 


\section{RESULTS}

During the study period (2013-2015), there were a total of 20138 deliveries in the hospital with an average of 6713 per year. Deliveries show a $21 \%$ increase over the last 3 years. Caesarean section comprised $52 \%$ of total deliveries and shows a $47 \%$ increase over 3 years. Live births show a similar $21 \%$ increase over 3 years. Still births comprised $3 \%$ of total births. (Table 1). The profile of babies as per birth weight show that $22.3 \%$ were Low Birth Weight (Birth weight $<2500 \mathrm{gm}$ ) and $11.6 \%$ were born preterm $(<37$ completed weeks of gestation).

Table 1: Showing the delivery load of Jorhat Medical College 2013-2015.

\begin{tabular}{|l|l|l|l|l|}
\hline Year & 2013 & 2014 & 2015 & Total \\
\hline $\begin{array}{l}\text { Total } \\
\text { deliveries }\end{array}$ & 6126 & 6618 & 7394 & 20138 \\
\hline C-section & 2888 & 3346 & 4241 & 10475 \\
\hline Live Birth & 5994 & 6479 & 7349 & 19713 \\
\hline Still birth & 184 & 215 & 218 & 617 \\
\hline
\end{tabular}

In the study period, total of 8069 babies were admitted in the SCNU of which 6104(75.6\%) were admitted in the inborn unit while 1965 (24.4\%) babies were admitted in the outborn unit. In the inborn unit, 59.5\% were of normal birth weight while $39.5 \%$ were LBW. In the outborn unit, $53.2 \%$ were normal birth weight while $46.8 \%$ were LBW.

As per birth criteria, overall $57.98 \%$ were $\geq 2.5 \mathrm{~kg}$ (Normal Birth Weight), 36.37\% were $1.5-2.49 \mathrm{~kg}$ (LBW) category, $4.9 \%$ were $1-1.49 \mathrm{~kg}$ (VLBW) category while $0.6 \%$ were $<1 \mathrm{~kg}$ (ELBW) category. (Table 2).As per gestation, preterm babies comprised $29 \%$ and $37 \%$ of admitted babies respectively in the inborn and outborn units. So, approximately half of the outborn cases were LBW babies.

Table 2: Profile of babies admitted to SCNU according to birth weight.

\begin{tabular}{|l|l|l|l|l|}
\hline $\begin{array}{l}\text { Birth } \\
\text { weight }(\mathrm{Kg})\end{array}$ & $\begin{array}{l}\text { Inborn( } \\
\mathrm{n}=6104)\end{array}$ & $\begin{array}{l}\text { Outborn}(\mathrm{n}= \\
1965)\end{array}$ & $\begin{array}{l}\text { Total }(\mathrm{n}= \\
8069)\end{array}$ & $\begin{array}{l}\% \\
\text { total }\end{array}$ \\
\hline$>2.5$ & 3633 & 1046 & 4679 & $57.98 \%$ \\
\hline $1.5-2.49$ & 2230 & 705 & 2935 & $36.37 \%$ \\
\hline $1-1.49$ & 215 & 184 & 399 & $4.9 \%$ \\
\hline$<1$ & 21 & 30 & 51 & $0.6 \%$ \\
\hline
\end{tabular}

The male: female ratio of admitted babies was $1.27: 1(55.98 \%$ vs $44.02 \%)$ and $1.55: 1(60.82 \%$ vs $39.18 \%$ ) in the inborn and outborn units respectively suggesting higher male admission in the outborn unit. (Table 3)

Table 3: Profile of admitted babies according to gender.

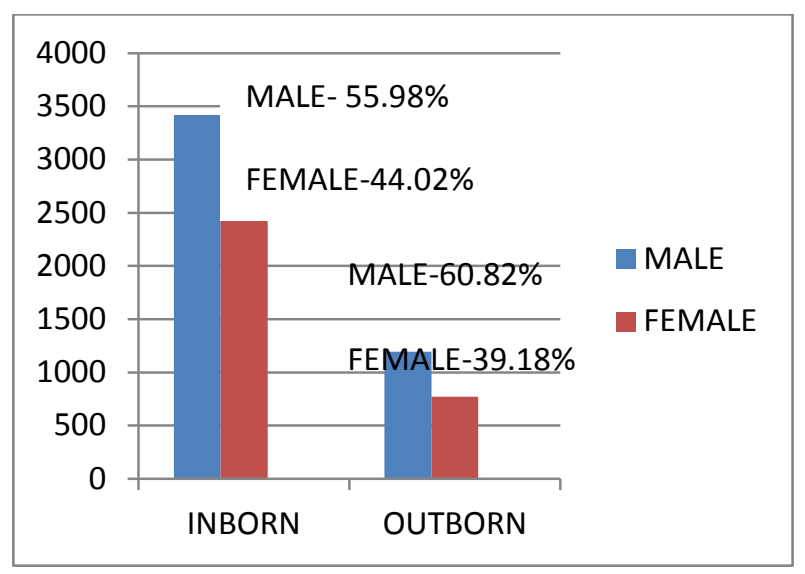

Morbidity profile of inborn neonates: (Table 4) Table 4: Showing the morbidity profile of admitted babies.

\begin{tabular}{|l|l|l|}
\hline Disease & Inborn & Outborn \\
\hline PT RDS & $260(4.3 \%)$ & $110(5.6 \%)$ \\
\hline MAS & $579(9.49 \%)$ & $38(1.9 \%)$ \\
\hline Other RDS & $548(8.9 \%)$ & $33(1.7 \%)$ \\
\hline Asphyxia & $1046(17.1 \%)$ & $302(15.4 \%)$ \\
\hline Sepsis & $1471(24.1 \%)$ & $784(39.9 \%)$ \\
\hline $\begin{array}{l}\text { Congenital } \\
\text { malformation }\end{array}$ & $81(1.3 \%)$ & $57(2.9 \%)$ \\
\hline Jaundice & $2158(35.4 \%)$ & $666(33.9 \%)$ \\
\hline Hypothermia & $18(0.3 \%)$ & $9(0.5 \%)$ \\
\hline Hypoglycaemia & $118(1.9 \%)$ & $37(1.9 \%)$ \\
\hline Others & $596(9.8 \%)$ & $217(11 \%)$ \\
\hline
\end{tabular}

In the inborn unit, Neonatal jaundice $(35.4 \%)$ was the most common cause of admission followed by sepsis (24\%) and birth asphyxia (17\%).Among respiratory morbidities, preterm RDS occurred in $4.2 \%$ cases while meconium aspiration syndrome (MAS) and TTNB occurred in $9.5 \%$ and $9 \%$ of babies respectively.

The overall incidence of RDS among preterm babies was $14.7 \%$ ( $n=260$ out of 1769).

Morbidity profile of outborn neonates:

Neonatal sepsis $(n=784)$ was the commonest cause of admission (39.9\%) followed by neonatal jaundice (33.9\%) and birth asphyxia (15.4\%). $5.6 \%$ of neonates presented with preterm RDS. 
Among other respiratory morbidities, MAS and TTNB were seen in $1.9 \%$ and $1.7 \%$ cases respectively. The overall incidence of RDS among preterm neonates was $15.2 \%(n=110$ out of 723$)$ which is similar to that of inborn neonates (14.7\%).

\section{Outcome of admitted patients: (Table 5)}

Table 5: Showing outcome of admitted babies.

\begin{tabular}{|l|l|l|}
\hline Outcome & Inborn $(\mathrm{n}=6104)$ & Outborn $(\mathrm{n}=1965)$ \\
\hline Discharge & $5273(86.4 \%)$ & $1456(74.1 \%)$ \\
\hline Referral & $76(1.2 \%)$ & $63(3.2 \%)$ \\
\hline LAMA & $353(5.8 \%)$ & $178(9.1 \%)$ \\
\hline Death & $402(6.6 \%)$ & $268(13.6 \%)$ \\
\hline
\end{tabular}

\section{Inborn patients:}

$87 \%(\mathrm{n}=5310)$ of inborn babies were successfully discharged from the unit. $5.8 \%$ of cases left against medical advice (LAMA) while $1.2 \%$ was referred mainly for surgical reasons as pediatric surgery facilities are not available in Jorhat Medical College.

The overall inborn mortality was $6.6 \%$ (male $7.3 \%$, female $5.5 \%$ ). The male female ratio is $1.7: 1$.

\section{Outborn patients:}

$72.6 \%$ (1426) of outborn babies were successfully discharged from the unit. $9.1 \%$ of cases left against medical advice (LAMA) while $3.2 \%$ was referred to AMCH, Dibrugarh.

The overall outborn mortality was $13.6 \%$ (male $13.3 \%$, female $14.1 \%$ ) which is twice that of the outborn mortality.

\section{Disease specific mortality: (Table 6)}

Table 6: Showing causes of mortality.

\begin{tabular}{|l|l|l|}
\hline Cause of death & $\begin{array}{l}\text { Inborn } \\
(\mathrm{n}=402)\end{array}$ & $\begin{array}{l}\text { Outborn } \\
(\mathrm{n}=268)\end{array}$ \\
\hline Preterm RDS & $54(13.4 \%)$ & $41(15.3 \%)$ \\
\hline MAS & $19(4.7 \%)$ & $8(3 \%)$ \\
\hline Birth asphyxia & $138(34.3 \%)$ & $65(24.2 \%)$ \\
\hline Sepsis & $150(37.3 \%)$ & $128(47.8 \%)$ \\
\hline Congenital malformation & $16(4 \%)$ & $8(3 \%)$ \\
\hline Extreme prematurity & $9(2.2 \%)$ & $5(1.9 \%)$ \\
\hline Others & $11(2.7 \%)$ & $10(3.7 \%)$ \\
\hline Cause not established & $5(1.2 \%)$ & $3(1.1 \%)$ \\
\hline
\end{tabular}

Among inborn cases, sepsis (37.3\%) was the commonest cause of death followed by birth asphyxia (34.3\%) and preterm RDS (13.4\%).

Outborn mortality also shows a similar pattern with sepsis (47.8\%), asphyxia (24.2\%) and preterm RDS (15.3\%) being the major causes of mortality.

Case fatality rate: (Table 7)

Table 7: Show case fatality rate of the causes of mortality

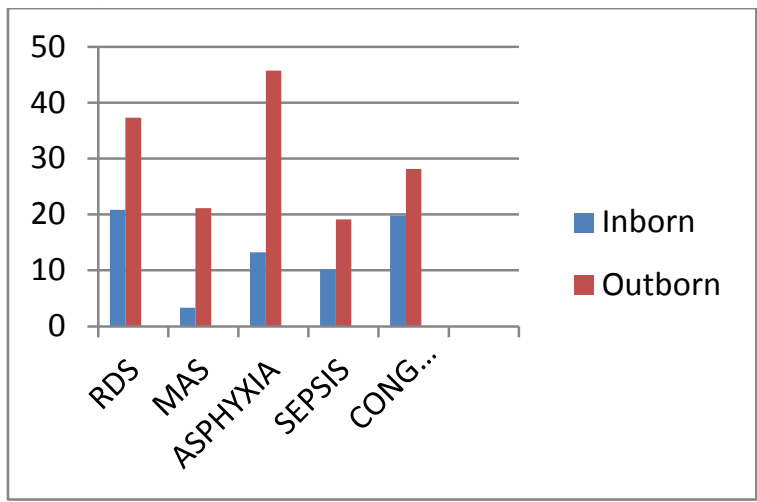

Among inborn cases, preterm RDS has the highest case fatality rate of $20.8 \%$ followed by major congenital malformation (19.8\%), asphyxia (13.2\%) and sepsis (10.2\%).

Among outborn cases, case fatality rate was highest in birth asphyxia (45.7\%) followed by preterm RDS (37.3\%), major congenital malformation $(28.1 \%)$, MAS $(21.1 \%)$ and sepsis $(19.1 \%)$.

The case fatality rates of all causes of mortality was higher in outborn compared to inborn babies.

Neonatal age at death shows that $83 \%$ of inborn and $72 \%$ of outborn deaths occurred in the first week of life (early neonatal death). (Table 8)

Of all neonates who expired in the SCNU, the distribution of birth weight show that $69.7 \%$ of inborn and $61.8 \%$ of outborn were less than < $2.5 \mathrm{~kg}$ (Table 9).

The proportional mortality according to birth weight shows that in the inborn babies, mortality in the normal birth weight category is only $3.4 \%$ which progressively increases with decreasing weight: LBW: 8.4\%, VLBW: 35\%, ELBW $76.2 \%$ ). The outborn unit shows $9.9 \%$ mortality among normal weight babies, $12.5 \%$ in LBW, $27.8 \%$ in VLBW and $63.3 \%$ in the ELBW category (Table 10). 


\section{JMSCR Vol||04||Issue||08||Page 11689-11695||August}

Table 8: Showing age at death.

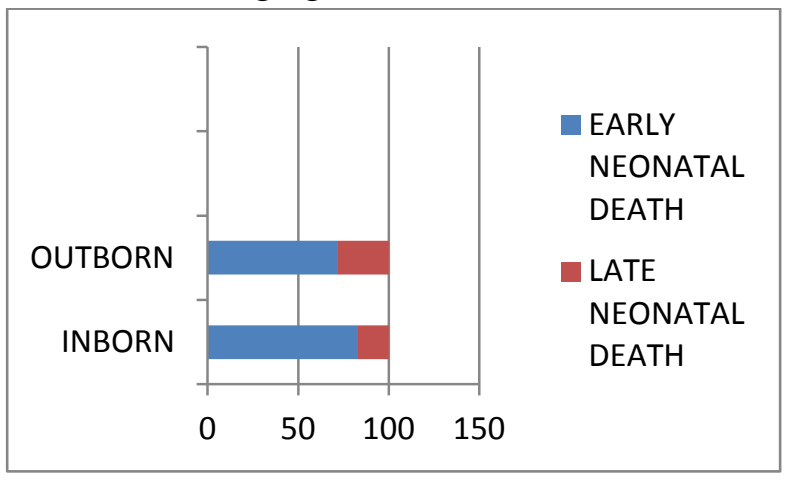

Table 9: Showing distribution of birth weight in death cases.

\begin{tabular}{|l|l|l|l|}
\hline $\begin{array}{l}\text { Birth } \\
\mathrm{wt}(\mathrm{kg})\end{array}$ & Inborn(n=402) & $\begin{array}{l}\text { Outborn } \\
(\mathrm{n}=265)\end{array}$ & $\begin{array}{l}\text { Total } \\
(\mathrm{n}=667)\end{array}$ \\
\hline$\geq 2.5$ & $122(30.3 \%)$ & $104(39.2 \%)$ & $226(33.9 \%)$ \\
\hline $1.5-2.49$ & $187(46.5 \%)$ & $88(33.2 \%)$ & $275(41.2 \%)$ \\
\hline $1-1.49$ & $77(19.2)$ & $54(20.4 \%)$ & $131(19.6 \%)$ \\
\hline$<1$ & $16(4 \%)$ & $19(7.2 \%)$ & $35(5.2 \%)$ \\
\hline
\end{tabular}

Table 10: Showing proportional mortality rate according to birth weight.

\begin{tabular}{|l|l|l|l|}
\hline $\begin{array}{l}\text { B.wt } \\
(\mathrm{kg})\end{array}$ & Inborn(n=402) & $\begin{array}{l}\text { Outborn } \\
(\mathrm{n}=265)\end{array}$ & Total $(\mathrm{n}=667)$ \\
\hline$\geq 2.5$ & $122 / 3633(3.4 \%)$ & $104 / 1046(9.9 \%)$ & $226 / 4679(4.8 \%)$ \\
\hline $1.5-2.49$ & $187 / 2230(8.4 \%)$ & $88 / 705(12.5 \%)$ & $275 / 2935(9.4 \%)$ \\
\hline $1-1.49$ & $77 / 220(35 \%)$ & $54 / 194(27.8 \%)$ & $131 / 414(31.6 \%)$ \\
\hline$<1$ & $16 / 21(76.2 \%)$ & $19 / 30(63.3 \%)$ & $35 / 51(68.6 \%)$ \\
& & & \\
\hline
\end{tabular}

\section{DISCUSSION}

The inborn versus outborn admission (75.6\%) vs $24.4 \%$ ) is comparable that reported by Sridhar et al $(71.7 \% \text { vs } 28.3 \%)^{[5]}$. The overall male female ratio( $58.4 \%$ male vs $41.6 \%$ female) is comparable to that reported by Niruprabha Saharia et al from Gauhati Medical College(male 60\%, female 40\%) ${ }^{[6]}$. LBW comprised $43.2 \%$ of the total admissions which is lower than that reported from SCNU Dibrugarh (49.7\%). The common morbidities seen in admitted babies are sepsis, jaundice and birth asphyxia. The incidence of sepsis is much higher in the outborn unit (40\%) compared to inborn (24\%). The NNPD has reported a similar rate of sepsis in extramural births $(39.7 \%){ }^{[7]}$. However, the overall incidence of sepsis in this study (34\%) is higher than that reported from a survey of eight SCNUs across the country by Neogi et al in 2009 $(18 \%)^{[8]}$. The higher incidence of sepsis may be related to unhygienic delivery practices in the periphery, overcrowding, lack of adequate manpower and non-compliance with asepsis during neonatal care.

The incidence of birth asphyxia is similar in both inborn and outborn (17\% vs $15.4 \%$ ) units; though it is higher than that of the NNPD data (8.3\%). Mani Kant Kumar et al reported $18.2 \%$ asphyxia among neonates admitted to a teaching hospital in Bihar ${ }^{[9]}$. The higher incidence of asphyxia may be related to delayed referral and lack of prompt intervention of high risk pregnancies and also lack of adequate neonatal resuscitation. The incidence of neonatal jaundice (inborn 35.4\%, outborn $33.9 \%$ ) is higher than that of other studies (Neogi et al (18\%), Sridhar et al 7\%). The incidence of preterm RDS (5.6\%) is lower than that reported by others- Mani Kumar et al $(9.7 \%)$, Sridhar et al (23.4\%), Rakholia et al (21.9\%).

The overall incidence of LAMA $(7.5 \%)$ is comparable to that of other studies (NNPD 7.5\%, Rakholia et al $8.3 \%)^{[10]}$.

The mortality data shows much higher mortality in outborn (13.6\%) compared to inborn (6.6\%). The higher outborn mortality highlights important issues like delayed referral, lack of pre-transport stabilisation and inadequate functioning of peripheral neonatal facilities like NBSUs. The overall mortality of the SCNU (10.2\%) is higher than that reported by Sridhar et al $(7.2 \%)$ but lower than Gauhati Medical College (13\%)- a teaching hospital of the state.

Birth specific mortality shows that among inborn babies $29.4 \%$ are normal birth weight while $70.6 \%$ are low birth weight. Similar results in the outborn unit show that majority of deaths are in the LBW category $(61.2 \%)$.

Gestation specific mortality shows that $56.5 \%$ of inborn and $50.7 \%$ of outborn deaths were preterm babies. Death among term babies was $3.9 \%$ in inborn and $10.4 \%$ in outborn. Death among preterm babies was higher- $12.8 \%$ in inborn and $18.7 \%$ in outborn babies.

Analysis of duration between admission and death shows that most of the deaths occurred between 1- 
3 days of admission (inborn 53.2\%, outborn $54.5 \%$ ) followed by 4-7 days (inborn $26.1 \%$, outborn $17.9 \%$ ). Sridhar et al reported majority of deaths at $<1$ day $(42.3 \%)$ followed by $1-3$ days of admission (40.2\%).

Analysis of age at death shows $83 \%$ of inborn deaths were early neonatal deaths (occurring in the $1^{\text {st }}$ week of life) with $5 \%$ occurring on day 1 of life. $17 \%$ deaths were late neonatal deaths $(>1$ week of life).In the outborn unit, $72 \%$ of deaths were early neonatal deaths $(5.7 \%$ on day 1 of life) while $28 \%$ deaths were late neonatal deaths. The overall percentage of early neonatal deaths of the SCNU $(77.5 \%)$ is comparable to national data (72.9\%) (SOIN 2014)

The disease specific mortality shows that sepsis (42.6\%), asphyxia (29.3\%) and prematurity $(17.5 \%)$ are the main causes of neonatal deaths in the unit. The outborn sepsis mortality $(47.8 \%)$ is higher than inborn $(37.3 \%)$ which is similar to that of NNPD (inborn $18.6 \%$ vs outborn $37.6 \%$ ). Birth asphyxia is responsible for $34.3 \%$ of deaths in inborn compared to $24.2 \%$ in the outborn unit. This is higher than that reported by Rakholia et al (inborn $16 \%$, outborn $21.4 \%$ ). Among prematurity related complications preterm RDS accounts for $17.5 \%$ of deaths. Major congenital malformation is responsible for $3.5 \%$ of total deaths which is lower than that of NNPD (7.8\%).

The analysis of case fatality rate shows $45.7 \%$ of birth asphyxia admitted in the outborn died as compared to only $13.2 \%$ in the inborn unit. Similar higher deaths due to other causes are also seen in the outborn versus inborn units: RDS (inborn: $20.8 \%$ vs outborn 37.3\%), sepsis (inborn $10.2 \%$ vs outborn $19.1 \%$ ), MAS (inborn: $3.3 \%$ vs outborn $21.1 \%$ ). The case fatality rate of the present study is higher than that reported by Chandrakala R Iyer et al from a teaching hospital of Andhra Pradesh ${ }^{[11]}$. The above data further highlights the deficiencies in neonatal care in the peripheral health facilities around the teaching hospital.

The outcome of admitted cases (according to birth weight) shows $4.8 \%$ mortality in the normal weight category which is lower than that reported by Modi $\mathrm{R}$ et al from a teaching hospital in Gujarat $(5.6 \%)$. However the mortality in the low birth weight category is comparatively higher in the present study ${ }^{[12]}$.

\section{Limitations of the study}

The present study being retrospective in nature could not analyse the epidemiological factors related to neonatal health especially socioeconomic background, maternal antenatal, intra natal and post natal factors that could have influenced the outcome. The morbidity and mortality data were dependent of the extent of data available retrospectively from case records and monthly reports. Newborns admitted into pediatric ward and PICU were not included in the study which could have influenced the results.

\section{CONCLUSION}

Birth asphyxia, sepsis and preterm RDS are the leading causes of mortality in our study. The outborn mortality is significantly higher than the inborn mortality. All the leading causes of mortality in the study are largely preventable. So there is urgent need to undertake necessary steps at multiple levels. Comprehensive antenatal care, antenatal corticosteroids, prompt management of high risk pregnancies, effective neonatal resuscitation, asepsis, functioning NBSU in the periphery, adequate manpower in neonatal care units are suggested measures. This will help in not only decreasing the neonatal morbidity and mortality but also to ensure intact survival.

\section{Funding: None \\ Conflict of interest: None.}

\section{REFERENCES}

1. Lawn JE, Cousens S, Zupan J; Lancet Neonatal Survival Steering Team.4 million deaths: when? Where? Why? Lancet 2005;2005;365: 891-900.

2. Toolkit for setting up of special care newborn units, stabilisation units and 
newborn corners. NewDelhi: United

Nations Children's Fund,2008.9p (http://www.unicef.org/India/SCNU_book 1_April_6 pdf, accessed on 12/05/2016).

3. Zodpey S, Paul VK:Public Health Foundation of India, AIIMS, Save the Children: State of India's Newborns (SOIN) report 2014; Last accessed on 19/06/2016.

4. Darmstadt GL, Bhutta ZA, Cousens S, Adam T, Walker N, de bernis L ; Lancet Neonatal Survival Steering Team. Evidence based, cost effective interventions: how many newborns can we save? Lancet 2005;365:977-88.

5. P V Sridhar, P S Thammanna, M Sandeep; Morbidity pattern and Hospital outcome of Neonates admitted in a Tertiary care Teaching Hospital, Mandya : International Journal of Scientific study; 2015; Vol3 , Issue 6: 126-129.

6. Niru Prabha Saharia, Arati Deka, Vivekananda MS; Mortality and Morbidity Pattern of Neonatal ICU of Gauhati Medical College and Hospital: IOSR Journal of Dental and Medical Sciences; Vol15,issue 6,VerXI(June 2016): 73-75.

7. Indian Council of Medical Research. National Neonatal Perinatal Database Network, New Delhi 2002-2003; ICMR, 2005:2437. (wwwnewbornwhocc.org, accessed 20/06/2016)

8. Sutapa Bandyopadhyay Neogi, Sumit Malhotra, Sanjay Zodpey, Pavitra Mohan; Assessment of Special Care Newborn Units in India: Journal of Health Population, Nutrition, 2011;Oct 29(5):500-509.

9. Mani Kant Kumar, Sachida Nand Thakur, Brish Bhanu Singh: Study of the morbidity and Mortality patterns in the Neonatal Intensive Care Unit at a Tertiary Care Teaching Hospital in Rohtas district, Bihar, India: Journal of Clinical and Diagnostic Research: 2012, April, Vol6(2): 282-285.
10. Ritu Rakholia, Vineeta Rawat, Mehar Bano, Gurpreet Singh: Neonatal morbidity and mortality of sick newborns admitted in a teaching hospital of Uttarakhand: CHRISMED Journal of Health and Research; Vol1,Issue4/Oct-Dec2014: 228-234.

11. Chandrakala R Iyer, Gornale VK, Harsha $\mathrm{P}$, Katwe $\mathrm{N}$ et al: Morbidity and Mortality pattern of neonatal care unit in a Medical College Hospital from South India: Pediatric Review, International Journal of Pediatric Research;Vol2,Issue 4,OctDec2015: 105-110.

12. Modi Rohit, Modi bhavesh, Patel Jaimin Kumar, K Margaret Punitha: Study of the Morbidity and Mortality Pattern in the Neonatal Intensive Care Unit at a Tertiary Care Teaching Hospital in Gandhinagar district, Gujarat, India: Journal of Research in Medical and Dental Sciences; Vol 3, Issue 3,July-Sep 2015: 208-212. 